\title{
SMP ISLAM TERPADU INSAN MADANI BANJARMASIN
}

\author{
Annadiana \\ Program Studi Teknik Arsitektur Fakultas Teknik Universitas Lambung Mangkurat \\ annaadianna@gmail.com \\ Prima Widia Wastuty \\ Program Studi Teknik Arsitektur Fakultas Teknik Universitas Lambung Mangkurat \\ primawidiawastuty@gmail.com
}

\begin{abstract}
ABSTRAK
Meningkatnya jumlah populasi penduduk di Banjarmasin dari tahun ke tahun berpengaruh pada meningkatnya kebutuhan untuk fasilitas pendidikan, dari segi kualitas maupun segi kuantitas. Selain pihak pemerintah, pihak swasta pun turut menyediakan fasilitas pendidikan formal. SMP Islam Terpadu Insan Madani Banjarmasin merupakan salah satu sekolah swasta di Banjarmasin. Namun pihak Yayasan belum menyediakan gedung sekolah yang sesuai standar dari pemerintah. Maka diperlukan rancangan SMP Islam Terpadu Insan Madani Banjarmasin yang sesuai dengan standar dan menciptakan suasana edukatif yang dapat mendukung proses pembelajaran umum, ke-Islam Terpaduan, dan kemampuan Tahfidz. Metode Architectural Programming milik William Pena dipilih untuk penyelesaian permasalahan arsitektural. Konsep Qur'an Educative Space merupakan rancangan SMPIT Insan Madani Banjarmasin yang menjadikan setiap ruang di sekolah ini sebagai tempat pembelajaran. Qur'an Educative Space diterapkan pada ruang luar dan ruang dalam, sehingga siswa dapat belajar di setiap ruang di sekolah tersebut dan dapat menghafal Al-Qur'an dengan baik.
\end{abstract}

Kata kunci: Edukatif, Sekolah Islam, Pendidikan

\begin{abstract}
The increasing number of population citizens in Banjarmasin from year to year has an effect on the increasing need for educational facilities, in terms of quality and quantity. Besides the government, the private sector also provides formal education facilities. Insan Madani Integrated Islamic Junior High School Banjarmasin is one of the private schools in Banjarmasin. But the Bina Insan Madani Foundation has not provided a school building that complies with government standards. It is necessary to design Insan Madani Integrated Islamic Junior High School Banjarmasin in accordance with the standards and create an educational atmosphere that can support the learning process. The Architectural Programming method of William Pena was chosen to solve the architectural problem. The Qur'an Educative Space Concept is a design of SMPIT Insan Madani Banjarmasin which makes every room in this school a place of learning. Qur'an Educative space is applied to outer space and inner space, so students can study in every room and memorize the Qur'an well in the school
\end{abstract}

Keywords: Educative, Islamic School, Education 


\section{PENDAHULUAN}

Pendidikan merupakan kebutuhan manusia yang terus-menerus berkembang seiring perkembangan zaman. Selain itu salah satu kewajiban Warga Negara Indonesia adalah wajib mengikuti pendidikan dari tingkat SD-SMP, hal tersebut telah tertulis dalam Undang-Undang Republik Indonesia Nomor 20 tahun 2003. Peran Pemerintah dalam pendidikan adalah dengan menyediakan lembaga pendidikan dari tingkat Sekolah Dasar, Sekolah Menengah Pertama, Sekolah Menengah Atas, hingga tingkat Perguruan Tinggi. Namun seiring meningkatnya jumlah populasi penduduk di Banjarmasin dari tahun ke tahun berpengaruh pada meningkatnya kebutuhan untuk fasilitas pendidikan, dari segi kualitas maupun segi kuantitas Maka dari itu selain pemerintah, pihak swasta turut serta dalam penyediaan lembaga pendidikan formal.

Sekolah sering disebut sebagai rumah kedua, hal tersebut disebabkan siswa(i) menghabiskan setengah waktunya dalam sehari dominan di sekolah. Oleh karenanya, kebanyakan orang tua bukan hanya memilih sekolah yang kurikulum pelajaran yang paling baik namun juga fasilitas sekolah yang lengkap untuk menunjang proses belajar anak-anaknya di sekolah. Saat ini selain mengajarkan pelajaran pengetahuan umum, materi di sekolah juga mengajarkan pelajaran keagamaan. Pentingnya pengetahuan agama harus dimulai sejak usia dini agar tidak terpengaruh oleh perkembangan zaman yang terdapat nilai negatif.

Saat ini sekolah berbasis agama Islam sudah banyak terdapat di seluruh kota di Indonesia, seperti MI, MTs, MA, Pondok Pesantren, dsb. Seiring berkembangnya zaman muncul lembaga pendidikan baru yang menggabungkan antara pelajaran pengetahuan umum dan pelajaran pengetahuan ke-Islam-an, yaitu Sekolah Islam Terpadu (SIT). Sekolah ini dibangun mulai dari tingkat Pendidikan Anak Usia Dini Islam Terpadu (PAUD IT), Sekolah Dasar Islam Terpadu (SDIT), Sekolah Menengah

Pertama Islam Terpadu (SMPIT), sampai dengan tingkat Sekolah Menengah Atas Islam Terpadu (SMAIT). Sekolah ini biasanya dibangun dalam satu kompleks agar pendidikan yang diajarkan selalu berkesinambungan dan lingkungan yang tercipta selalu terkontrol dan agamis.

\section{Tabel 1 Daftar Sekolah Islam Terpadu di} Banjarmasin

\begin{tabular}{|c|c|c|}
\hline Nama Yayasan & Tingkat Sekolah & Jumlah \\
\hline \multirow[t]{6}{*}{$\begin{array}{l}\text { Yayasan } \\
\text { Ukhuwah }\end{array}$} & $\begin{array}{l}\text { KB Islam Terpadu } \\
\text { Ukhuwah }\end{array}$ & \multirow[t]{6}{*}{6} \\
\hline & $\begin{array}{l}\text { TK Islam } \quad \text { Terpadu } \\
\text { Ukhuwah }\end{array}$ & \\
\hline & $\begin{array}{l}\text { TPA Islam Terpadu } \\
\text { Ukhuwah }\end{array}$ & \\
\hline & $\begin{array}{l}\text { SD Islam } \quad \text { Terpadu } \\
\text { Ukhuwah }\end{array}$ & \\
\hline & $\begin{array}{l}\text { SMP Islam Terpadu } \\
\text { Ukhuwah }\end{array}$ & \\
\hline & $\begin{array}{l}\text { SMA Islam Terpadu } \\
\text { Ukhuwah }\end{array}$ & \\
\hline \multirow{3}{*}{$\begin{array}{l}\text { Yayasan } \\
\text { Permata } \\
\text { Mulia }\end{array}$} & $\begin{array}{l}\text { KB Islam Terpadu Permata } \\
\text { Hati }\end{array}$ & \multirow[t]{3}{*}{3} \\
\hline & $\begin{array}{l}\text { TK Islam Terpadu Permata } \\
\text { Hati }\end{array}$ & \\
\hline & $\begin{array}{ll}\text { TPA Islam } & \text { Terpadu } \\
\text { Permata Hati } & \end{array}$ & \\
\hline \multirow{4}{*}{$\begin{array}{l}\text { Yayasan } \\
\text { Permata } \\
\text { Jannati }\end{array}$} & \multirow{2}{*}{$\begin{array}{l}\text { KB Islam Terpadu Permata } \\
\text { Jannati } \\
\text { TK Islam Terpadu Permata } \\
\text { Jannati }\end{array}$} & \multirow[t]{4}{*}{4} \\
\hline & & \\
\hline & $\begin{array}{ll}\text { TPA Islam } & \text { Terpadu } \\
\text { Permata Jannati } & \end{array}$ & \\
\hline & $\begin{array}{l}\text { SD Islam Terpadu Permata } \\
\text { Jannati }\end{array}$ & \\
\hline \multirow{4}{*}{$\begin{array}{l}\text { Yayasan Cipta } \\
\text { Insan Paripurna }\end{array}$} & KB SBB Hunafaa & \multirow[t]{4}{*}{4} \\
\hline & TK Hunafaa & \\
\hline & TPA Hunafaa & \\
\hline & SD Islam Terpadu Hunafaa & \\
\hline \multirow{3}{*}{$\begin{array}{l}\text { Yayasan } \\
\text { Pendidikan } \\
\text { Sosial Nurul } \\
\text { Fikri }\end{array}$} & $\begin{array}{l}\text { TK Islam Terpadu Nurul } \\
\text { Fikri }\end{array}$ & \multirow[t]{3}{*}{3} \\
\hline & $\begin{array}{l}\text { SD Islam Terpadu Nurul } \\
\text { Fikri }\end{array}$ & \\
\hline & $\begin{array}{l}\text { SMP Islam Terpadu Nurul } \\
\text { Fikri }\end{array}$ & \\
\hline \multirow[t]{5}{*}{$\begin{array}{l}\text { Yayasan Bina } \\
\text { Insan Madani }\end{array}$} & $\begin{array}{l}\text { KB Islam Terpadu } \\
\text { Al-Firdaus }\end{array}$ & \multirow[t]{5}{*}{5} \\
\hline & $\begin{array}{ll}\text { TK Islam } & \text { Terpadu } \\
\text { Al-Firdaus } & \end{array}$ & \\
\hline & $\begin{array}{l}\text { TPA Islam Terpadu } \\
\text { Al-Firdaus }\end{array}$ & \\
\hline & $\begin{array}{l}\text { SD Islam } \quad \text { Terpadu } \\
\text { Al-Firdaus }\end{array}$ & \\
\hline & $\begin{array}{l}\text { SMP Islam Terpadu Insan } \\
\text { Madani }\end{array}$ & \\
\hline
\end{tabular}


Di Banjarmasin sudah berdiri 25 Sekolah Islam Terpadu dari tingkat Pendidikan Anak Usia Dini Islam Terpadu (PAUDIT) hingga Sekolah Menengah Atas Islam Terpadu (SMAIT), 5 diantaranya adalah PAUDIT (KB, TK, dan TPA) Al-Firdaus, SDIT Al-Firdaus, dan SMPIT Insan Madani. Ketiga sekolah tersebut berada dibawah Yayasan Bina Insan Madani Banjarmasin. Yayasan Bina Insan Madani ini sudah berdiri sejak tahun 2012 yang diawali dengan berdirinya SDIT Al-Firdaus dan PAUD IT Al-Firdaus. Lalu pada tahun 2018 didirikan SMPIT Insan Madani dengan program tambahan asrama khusus untuk putra.

Sama seperti pada tingkat PAUD dan SDIT AI-Firdaus, SMPIT Insan Madani juga menerapkan pembelajaran dengan kurikulum Umum dan kelslaman dengan tambahan program tahfidz Al-Qur'an. Keadaan SMP Islam Terpadu Insan Madani Banjarmasin masih belum memadai dari segi kuantitas ruang kelas, hal tersebut dapat dilihat dari fasilitas kelas untuk tingkat SMP yang masih bergabung dengan gedung tingkat SD. Selain itu, juga diperlukan fasilitas penunjang seperti Perpustakaan, Laboratorium IPA, Laboratorium Bahasa, dan Laboratorium Komputer.

Salah satu faktor yang dapat membuat suatu aktivitas dapat dilakukan secara optimal adalah ketersediaan sarana dan prasarana yang mencukupi. Untuk menunjang proses belajar, sarana dan prasarana sangat diperlukan siswa di sekolah. Sarana dan prasarana yang diperlukan pada suatu sekolah berupa ruang kelas, perpustakaan, laboratorium, dll. Hal ini bertujuan agar mendukung suasana edukatif dapat tercipta di lingkungan SMP Islam Terpadu Insan Madani Banjarmasin dan memacu semangat siswa dalam proses pembelajaran.

\section{PERMASALAHAN}

Permasalahan yang diangkat adalah Bagaimana rancangan SMPIT Insan
Madani Banjarmasin dengan ruang-ruang yang edukatif untuk menunjang pembelajaran umum, ke-Islam Terpadu-an, dan kemampuan Tahfidz.

\section{TINJAUAN PUSTAKA}

\section{A. Tinjauan SMP Islam Terpadu}

Sekolah Islam Terpadu (SIT) merupakan lembaga pendidikan yang didirikan oleh Lembaga Yayasan Islam. Sekolah ini menerapkan pendidikan umum yang berlandaskan pada Al-Qur'an dan As-Sunnah. Sekolah ini menggabungkan pelajaran pengetahuan umum dan pelajaran pengetahuan ke-Islam-an, serta pesantren dalam penyelenggaraan kurikulumnya. Selain itu, Sekolah Islam Terpadu juga menggabungkan pendidikan intelektual, jiwa/psikologis, dan fisik.

Sekolah Islam Terpadu dibangun dalam satu kompleks yang terdiri Pendidikan Anak Usia Dini Islam Terpadu (PAUD IT), Sekolah Dasar Islam Terpadu (SDIT), Sekolah Menengah Pertama Islam Terpadu (SMPIT), dan berlanjut hingga Sekolah Menengah Atas Islam Terpadu (SMAIT). Hal tersebut bertujuan agar proses pendidikan tetap berkesinambungan dan terkontrol dengan baik. Sekolah Islam Terpadu bertujuan untuk menjadikan siswa(i)nya memiliki pengetahuan umum yang kompeten diimbangi dengan pengetahuan agama yang mumpuni dan berakhlak mulia. Sistem pendidikan di SMPIT memadukan antara program pendidikan umum dan agama namun tetap seimbang diantara keduanya.

\section{B. Visi dan Misi SMPIT Insan Madani}

- Visi

"Mengupayakan terbentuknya generasi Hafidz Qur'an, berakhlak mulia, berwawasan luas, kreatif dan memiliki spirit kepemimpinan yang baik."

- Misi

a) Mengembangkan sistem pondok pesantren berbasis Tahfidz Qur'an

b) Membudayakan kehidupan santri yang dilandasi akhlak mulia 
c) Menyediakan sarana pengembangan diri untuk mengembangkan wawasan dan kreatifitas santri

d) Membiasakan kehidupan pondok yang membangun kepemimpinan santri

\section{Kurikulum SMP Islam Terpadu}

$\begin{array}{lcr}\text { Kurikulum untuk tingkat } & \text { SMP/MTs } \\ \text { yang digunakan sesuai dengan }\end{array}$ PERMENDIKBUD No.35 Tahun 2018 yaitu Kurikulum 2013. Kompetensi inti SMP/MTs adalah kemampuan untuk siswa(i) dalam mencapai Standar Kompetensi Lulusan (SKL) yang harus dimiliki siswa SMP/MTs pada setiap tingkat kelas. Notasi yang digunakan untuk Kompetensi Inti yaitu:

a. KI-1 untuk sikap spiritual

b. KI-2 untuk sikap sosial

c. KI-3 untuk pengetahuan

d. KI-4 untuk keterampilan

Kurikulum SMPIT tetap berlandaskan pada kurikulum dari Kementrian Pendidikaan dan Kebudayaan yang diintegrasikan dengan nilai-nilai agama. Selain pendidikan umum dan pendidikan agama, di SMPIT juga terdapat pendidikan pengembangan diri. Struktur kurikulum yang terdapat di SMPIT Insan Madani Banjarmasin sebagai berikut:

a. Pendidikan umum

- Matematika

- Bahasa Indonesia

- Bahasa Inggris

- PKn

- IImu Pengetahuan Alam (IPA)

- IImu Pengetahuan Sosial (IPS)

- Pendidikan Agama Islam (PAI)

- Seni Budaya dan Kesenian (SBK)

- Pendidikan Jasmani Olahraga dan Kesehatan (PJOK)

- Muatan Lokal

b. Pendidikan ke-Islam Terpaduan

Pendidikan ini merupakan kurikulum penunjang dalam Sekolah Islam Terpadu. Mata pelajarannya yaitu:

- Nahwu

- Shorof

- Fiqih

c. Program Tahfidz Al-Qur'an

Program tahfidz ini merupakan program hafalan Al-Qur'an yang dilanjutkan dari tingkat SDIT yang mana merupakan syarat untuk lulus sekolah.

d. Program pengembangan diri

Program ini lebih dikenal dengan sebutan ekstrakurikuler. Program pengembangan diri yang terdapat yaitu pramuka dan Taekwondo.

\section{Sarana dan Prasarana Sekolah Islam Terpadu}

Sarana adalah alat-alat yang dipakai sebagai pendukung pembelajaran yang dapat dipindah-pindah, sedangkan prasarana adalah pendukung utama yang diperlukan dalam menjalankan proses pembelajaran. Standar sarana dan prasarana yang dapat mendukung proses pembelajaran pengguna Sekolah Islam Terpadu terdapat dalam PERMENDIKNAS No. 24 tahun 2007.

a. Kelompok Pendidikan

Satu SMP memiliki paling sedikit 3 rombel dan paling banyak 24 rombel.

b. Lahan

Luas lahan minimum mampu untuk menampung minimal 3 rombel. Lahan efektif untuk didirikan bangunan, tempat bermain atau berolahraga, dan tempat upacara. Lahan bebas dari potensi bahaya, memiliki kemiringan lahan kurang dari $15 \%$, memiliki akses penyelamatan saat darurat, dan lahan tidak dalam sengketa.

\section{c. Bangunan}

Bangunan gedung berdasarkan ketentuan tata bangunan yaitu KDB maksimum 30\%, KLB dan ketinggian bangunan yang telah ditetapkan dalam RTRW, dan jarak bebas bangunan gedung yang meliputi GSB gedung yang telah ditetapkan dalam Peraturan Daerah.

Bangunan juga harus memiliki ketentuan keselamatan yaitu memiliki struktur yang kokoh dan dapat menahan kekuatan alam seperti gempa dan lainnya, dilengkapi sistem proteksi pasif dan/atau pengamanan aktif untuk mencegah dan menanggulangi bahaya kebakaran dan petir. Bangunan gedung harus memiliki ventilasi udara yang cukup dan pencahayaan yang memadai. Bangunan 
juga harus memiliki sistem sanitasi di dalam dan di luar bangunan untuk memenuhi sanitasi air bersih, air kotor (grey water atau black water), penyaluran air hujan, dan pembuangan sampah.

d. Ruang-ruang.

- Ruang kelas

- Ruang pimpinan

- Ruang guru

- Ruang tata usaha

- Perpustakaan

- Laboratorium

- Masjid

- Ruang konseling

- Ruang UKS

- Fasilitas olahraga

- Toilet

- Ruang organisasi siswa

- Gudang

- Ruang sirkulasi

\section{E. Tinjauan Ruang Edukatif}

\section{Ruang}

Ruang (space) berasal dari kata spasium. Ruang merupakan rongga yang dibatasi permukaan bangunan. Ruang merupakan bentuk 3 dimensi yang memiliki permukaan luas yang terus memanjang ke segala arah dan berisikan sesuatu. Ada 2 macam ruang, yaitu:

- Ruang Luar

Ruang luar berarti sebagai lingkungan luar buatan manusia. Elemen pembentuk ruang luar antara lain: soft material (tanaman/pohon dan air), hard material (kayu, batu-batuan, pasir, batu bata, batu kali, aluminium, besi, perunggu, tembaga, baja, plastik/fiberglass, beton dan plywood), dan signage (penunjuk arah, signage biasanya diletakkan di tempat yang terlihat dan tinggi).

- Ruang Dalam

Ruang dalam merupakan buatan manusia yang dibentuk oleh rangkaian bidang-bidang yang digunakan manusia untuk beraktivitas. Elemen-elemen pembentuk ruang dalam antara lain: Bidang horizontal bawah/lantai (struktur lantai, slab lantai, dan penutup lantai. Lantai dapat dijadikan sebagai alat ukur, bidang bertekstur, jalur pemandu, panggung, sumber bunyi, atau berundak), bidang horizontal/plafon (plafon dapat dirancang dari ketinggiannya, bentuknya, warna, dan tekstur serta plafon dapat dibuat sebagai bidang untuk grafiti, layar proyektor, atau tempat display), bidang vertikal/dinding (grafiti, layar proyektor, tempat display, cermin, alat ukur, sumber suara, bidang untuk ditulis/dicoret/digambar/diwarna, atau sebagai bidang bermagnet).

\section{Edukatif}

Edukatif berasal dari kata edukasi yang memiliki arti mendidik. Konsep edukatif biasanya diterapkan pada bangunan pendidikan, hal ini bertujuan agar mendukung proses belajar. Bentuk penerapannya dapat berupa penyediaan berbagai macam sarana dan prasarana yang mencukupi, serta sumber informasi yang lengkap.

\section{Ruang Edukatif}

Menurut Wastuty (2019), Ruang sebagai Media Pembelajaran merupakan ruang yang tidak hanya menjadi wadah edukasi namun juga dapat membantu pendidik dalam memberikan edukasi. Perlakuan elemen ruang dapat dikombinasikan sesuai dengan keperluan dalam kebutuhan pembelajaran. Penerapan elemen-elemen pembentuk ruang bukan hanya diterapkan pada ruang dalam namun juga dapat diterapkan pada ruang luar. Elemen-elemen pembentuk ruang pembelajaran yaitu dinding, plafon, lantai, dan tata letak perabot (furniture).

\section{METODE}

milik William Prchitectural Programming penyelesaian permasalahan arsitektural karena metode ini menekankan pada identifikasi permasalahan dalam perancangan SMP Islam Terpadu Insan Madani Banjarmasin. Metode ini menghasilkan keefisienan, kejelasan, dan keekonomisan dalam proses pemecahan masalah maupun dalam perancangan. Metode programming Pena memiliki lima 
tahap yaitu menentukan tujuan (Establish Goals), mengumpulkan dan menganalisis fakta (Collect and Analyze Facts), menemukan dan menghasilkan konsep
(Find and Develop Concepts), menentukan kebutuhan (Determine Needs), dan menyatakan permasalahan (State the Problem).

Tabel 3 Penerapan Metode Architectural Programming

\begin{tabular}{|c|c|c|c|c|}
\hline Tujuan & Fakta & Konsep & Kebutuhan & Permasalahan \\
\hline $\begin{array}{l}\text { Rancangan SMPIT Insan } \\
\text { Madani Banjarmasin } \\
\text { bertujuan agar setiap } \\
\text { ruang-ruang di sekolah ini } \\
\text { dapat menjadi media } \\
\text { pembelajaran untuk siswa. }\end{array}$ & $\begin{array}{l}\text { SMPIT Insan Madani } \\
\text { Banjarmasin masih belum } \\
\text { memadai dari } \\
\text { ketersediaan ruang kelas } \\
\text { karena bertambahnya } \\
\text { siswa setiap tahun ajaran } \\
\text { baru. }\end{array}$ & $\begin{array}{l}\text { Konsep yang } \\
\text { diterapkan adalah } \\
\text { menjadikan } \\
\text { ruang-ruang di sekolah } \\
\text { sebagai ruang yang } \\
\text { edukatif } \\
\text { menunjang untuk } \\
\text { dalam belajar. }\end{array}$ & $\begin{array}{l}\text { Ruang kelas dan } \\
\text { fasilitas penunjang } \\
\text { untuk proses } \\
\text { belajar seperti } \\
\text { laboratorium dan } \\
\text { perpustakaan. }\end{array}$ & $\begin{array}{lr}\text { SMPIT Insan } & \text { Madani } \\
\text { Banjarmasin } & \text { belum } \\
\text { terciptanya ruang-ruang } \\
\text { yang edukatif } & \text { untuk } \\
\text { menunjang } & \text { proses } \\
\text { pembelajaran. } & \end{array}$ \\
\hline
\end{tabular}

Sumber: Analisis Penulis, 2019

\section{PEMBAHASAN}

\section{A. Konsep Programatik}

Berdasarkan permasalahan yang
telah disebutkan yaitu Bagaimana
rancangan SMPIT Insan Madani
Banjarmasin yang sesuai dengan standar
dan menciptakan suasana edukatif yang
mendukung proses pembelajaran, maka
jawaban untuk permasalahan tersebut
adalah penerapan Qur'an Educative Space.

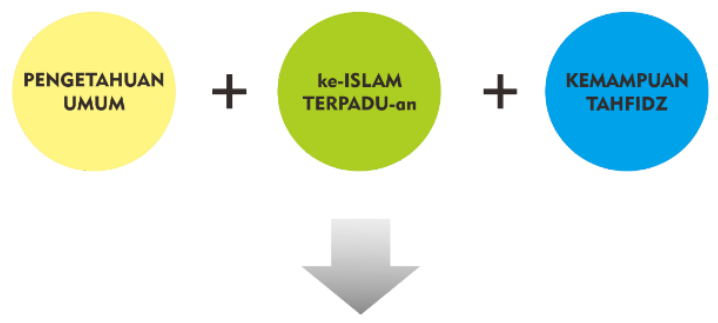

QUR'AN EDUCATIVE SPACE :

Gambar 1 Konsep Programatik

Konsep Qur'an Educative Space adalah penerapan ruang yang dapat memotivasi siswa dalam proses pembelajaran. Konsep Qur'an Educative Space bertujuan untuk mentransferkan ilmu ke siswa(i) melalui ruang-ruang, selain itu ruang-ruang di sekolah juga bertujuan untuk memudahkan siswa dalam kemampuan tahfidz.

Konsep ini diterapkan pada ruang luar dan ruang dalam bangunan. Hal ini bertujuan agar siswa dapat belajar bukan hanya didalam ruang namun juga di luar ruang. Penerapan konsep ini melalui penggunaan elemen-elemen pembentuk ruang seperti dinding, plafon, lantai, furniture, hard material, soft material, dll.

\section{B. Konsep Rancangan}

\section{Tata Massa}

Tata massa bangunan menyesuaikan dengan tipologi bangunan di lingkungan Komplek Yayasan Bina Insan Madani yang merupakan bangunan SDIT Al-Firdaus, PAUD IT Al-Firdaus, dan asrama putra SMPIT Insan Madani. Penyesuaian bentuk tipologi dengan bangunan sekitar bertujuan agar bangunan SMPIT Insan Madani bentuknya masih selaras dengan bangunan sekitarnya di Komplek Yayasan Bina Insan Madani.

Ketinggian level bangunan mengikuti ketinggian bangunan di sekitar yang rata-rata memiliki jumlah lantai 2 tingkat. Jumlah lantai dibuat 2 tingkat bertujuan agar siswa tidak mudah lelah dalam pencapaian ke ruang kelas atau ruang lainnya.

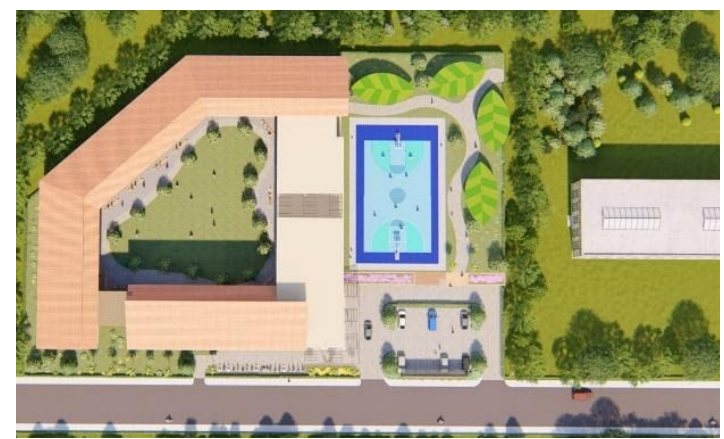

Gambar 2 Site Plan 


\section{Konsep Zoning Ruang Dalam}

Zoning di ruang dalam dibagi menjadi 4 zona, yaitu zoning ruang pembelajaran, zoning ruang penunjang, zoning ruang kantor, dan zoning ruang servis. Pembagian zoning berdasarkan sesuai kebutuhan keheningan dan zoning penerima. Zona ruang kantor diletakkan di paling depan bangunan bertujuan agar orangtua siswa bisa langsung menuju ruang kantor tanpa kebingungan mencari. Zona ruang penunjang adalah zona yang bersifat semi publik untuk ruang dalam, zona ini dapat diakses oleh siswa, guru, staf, dan orangtua siswa. Zona servis dipecah beberapa bagian sesuai dengan kebutuhan. Yang terakhir adalah zona pembelajaran, zona pembelajaran diletakkan di bagian belakang bertujuan agar tidak bising.

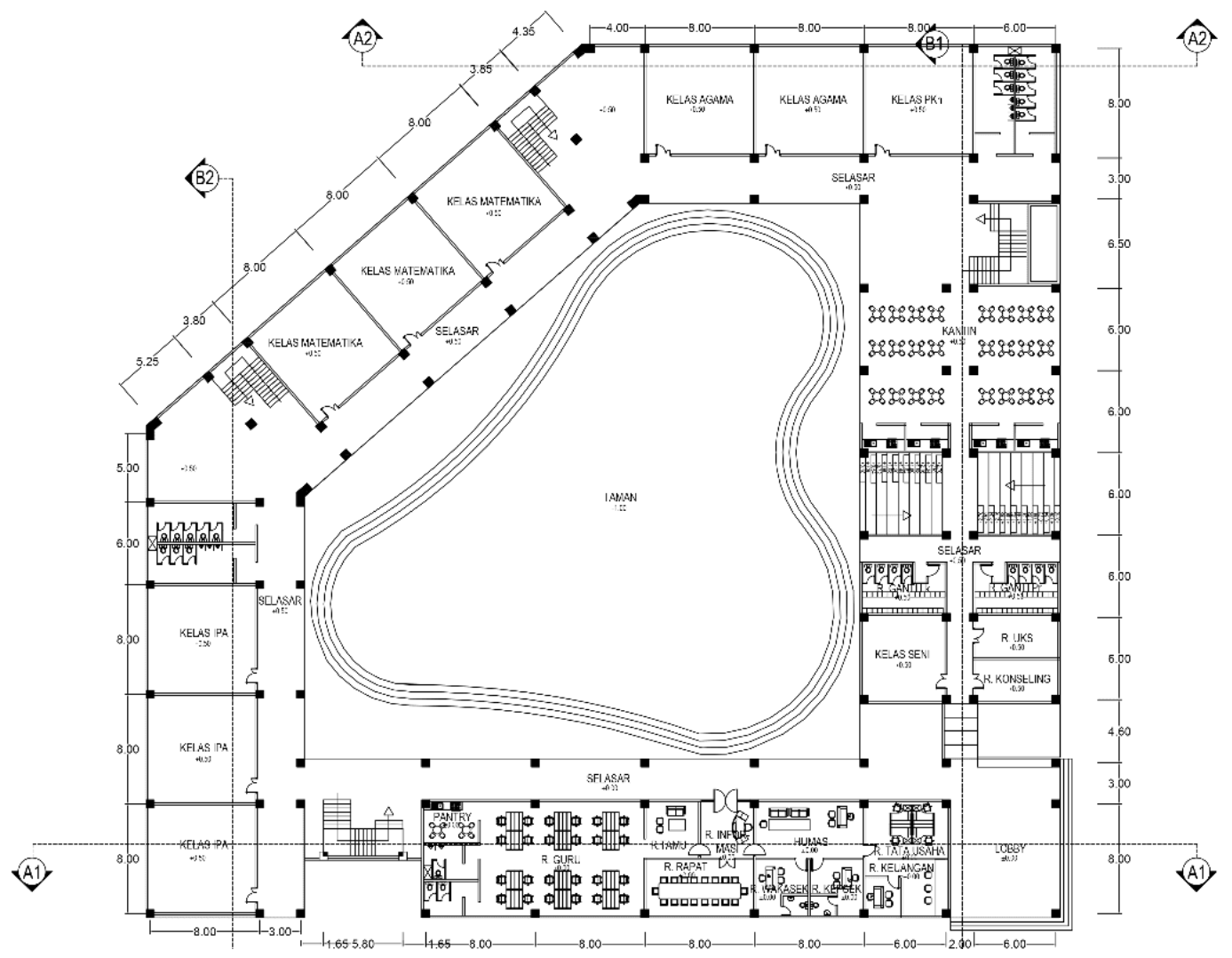

Gambar 3 Denah Lantai 1 SMPIT Islam Madani 


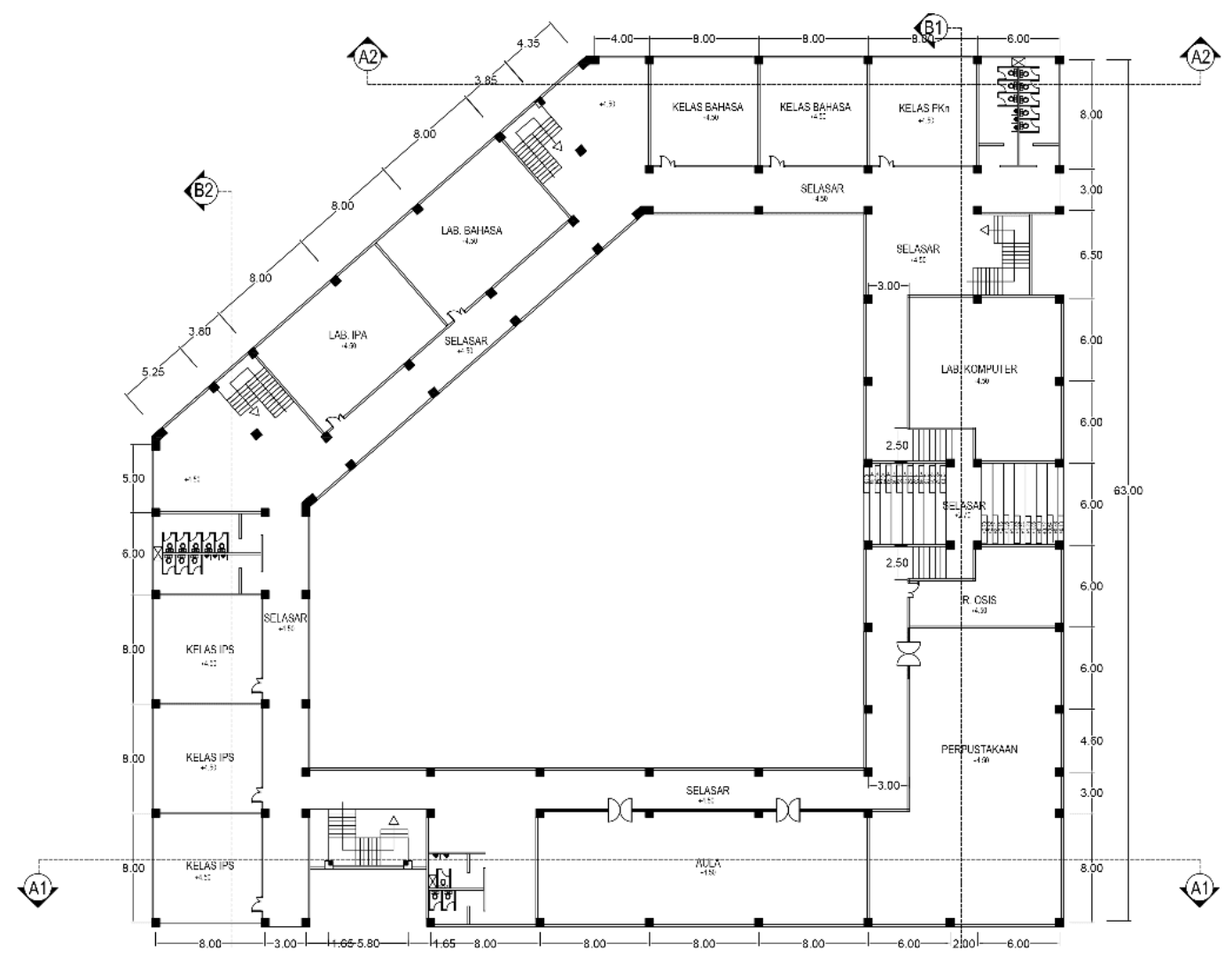

Gambar 4 Denah Lantai 2 SMPIT Islam Madani

\section{Konsep Zoning Ruang Luar}

Ruang luar pada bangunan dibagi menjadi 2 zoning. Zoning tersebut adalah zoning publik dan zoning semi publik. Zoning publik adalah zoning yang dapat diakses oleh siswa, guru, staf, orangtua siswa, dan tidak ada ketentuan khusus. Zoning semi publik adalah zoning yang hanya dapat diakses oleh siswa, guru, atau staff dari SMPIT Insan Madani.

Zoning publik dimanfaatkan sebagai area parkir mobil, parkir sepeda motor, dan ruang terbuka. Area parkir mobil dan sepeda motor diletakkan pada bagian depan site. Ruang terbuka digunakan untuk upacara atau taman yang digunakan orangtua saat menjenguk siswa. Ruang terbuka diletakkan pada bagian depan site.

Zona semi publik digunakan sebagai lapangan bermain atau olahraga yaitu lapangan basket dan lapangan futsal. Ruang bermain dan olahraga diletakkan pada bagian timur site. Perletakkan ruang bermain dan olahraga di bagian timur sebagai pemisah antara gedung SMPIT Insan Madani dengan gedung SDIT Al-Firdaus. Hal ini bertujuan agar saat jam pelajaran suara dari gedung satu ke gedung lainnya tidak saling terdengar.

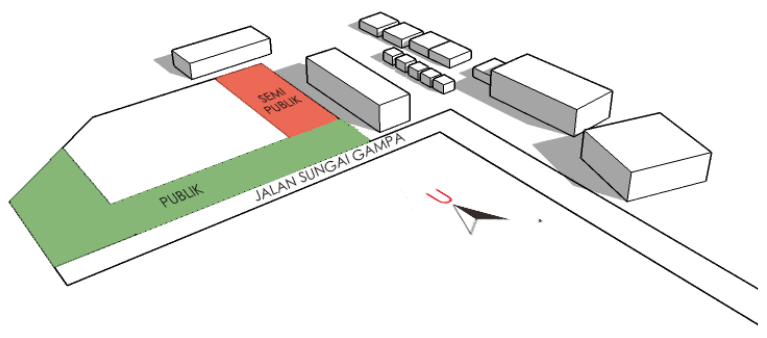

Gambar 5 Zoning Ruang Luar

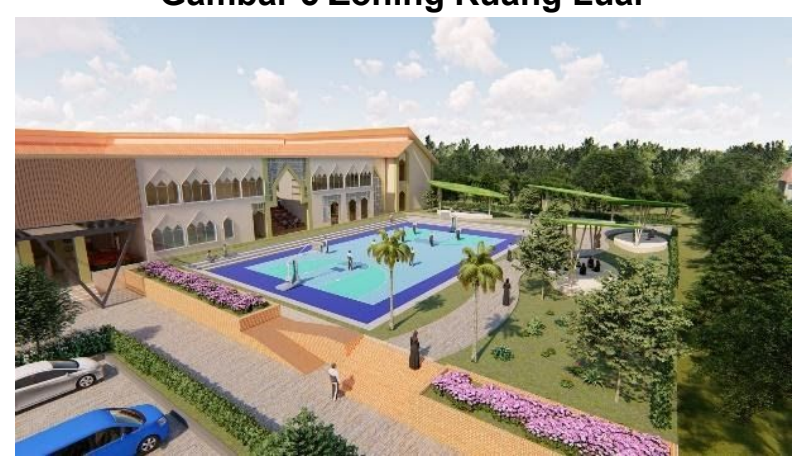

Gambar 6 Taman 


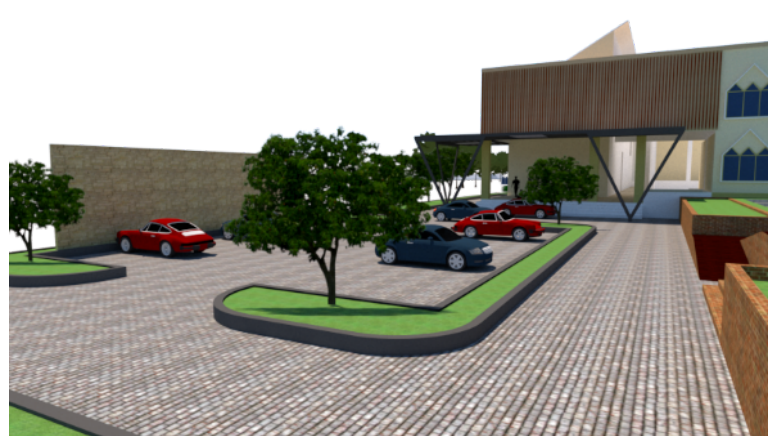

Gambar 7 Parkir Mobil

\section{Aspek Interior}

Aspek interior (ruang dalam) dirancang pada elemen dinding, plafon, lantai, dan penataan perabot yang sangat berkaitan dengan Konsep Qur'an Educative Space. Elemen-elemen tersebut diterapkan melalui material, warna, tekstur, dan tata letak. Konsep Qur'an Educative Space pada aspek interior (ruang dalam) agar siswa di sekolah dapat menciptakan suasana, motivasi, dan semangat belajar. Ruang dalam digunakan sebagai ruang pembelajaran formal seperti ruang kelas, perpustakaan, dan laboratorium.

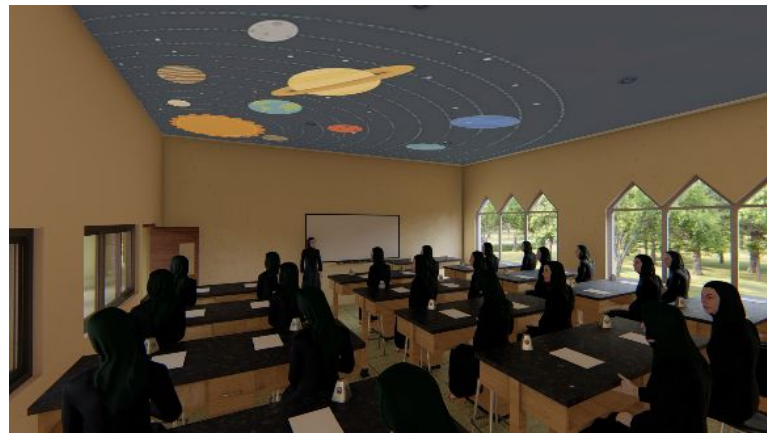

Gambar 8 Ruang Kelas IPA

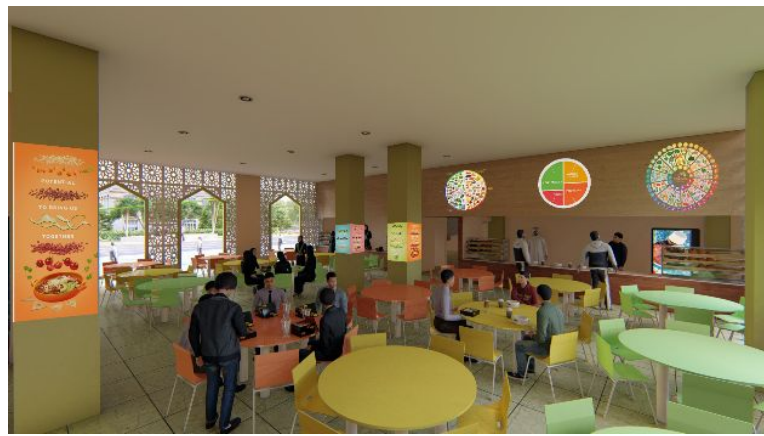

Gambar 9 Kantin

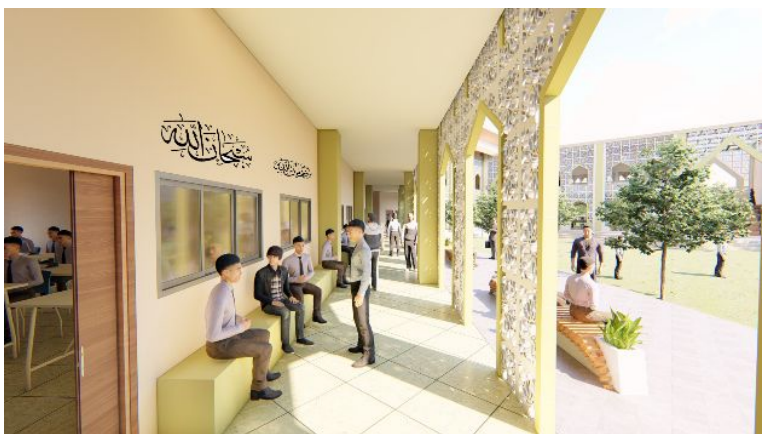

Gambar 10 Selasar

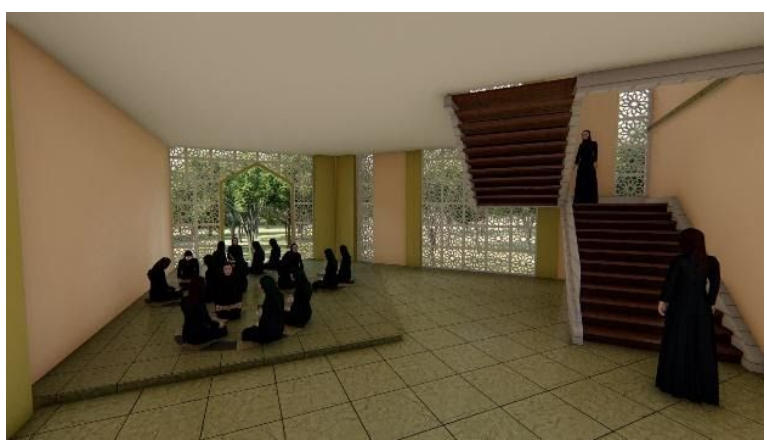

Gambar 11 Pocket Space

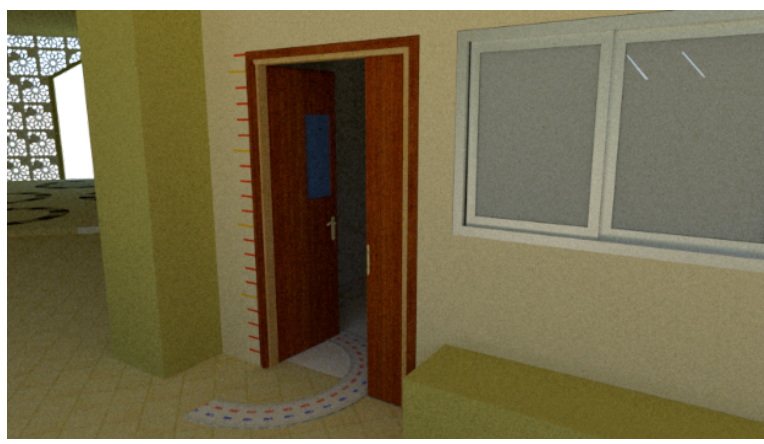

Gambar 12 Lantai Kelas Matematika

\section{Aspek Eksterior}

Aspek eksterior (ruang luar) dirancang pada lansekap. Elemen-elemen ruang luar berupa hard material, soft material, furniture, dan signage. Sama seperti pada aspek interior, pada aspek eksterior elemen-elemen ruang luar diterapkan melalui material, tekstur, tata letak, dan warna. Ruang luar digunakan sebagai ruang pembelajaran formal yang aktivitasnya di luar seperti pelajaran olahraga dan sebagai ruang pembelajaran informal seperti untuk menghafal Al-Qur'an. Furniture taman berupa bangku taman dan gazebo. Furniture taman harus dapat digunakan secara multifungsi. 


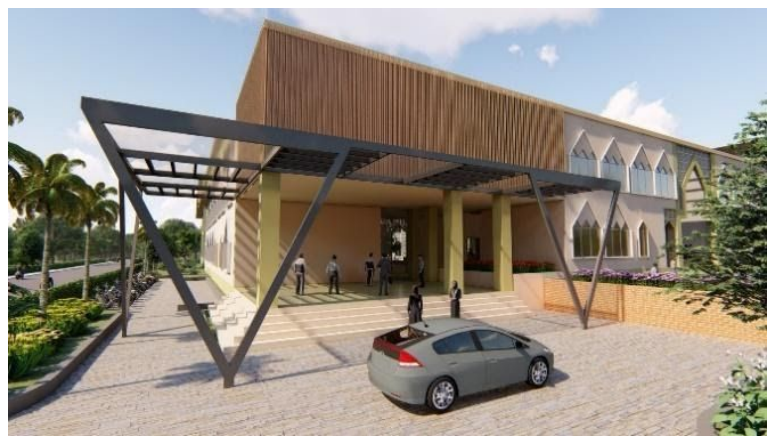

Gambar 13 Drop Off

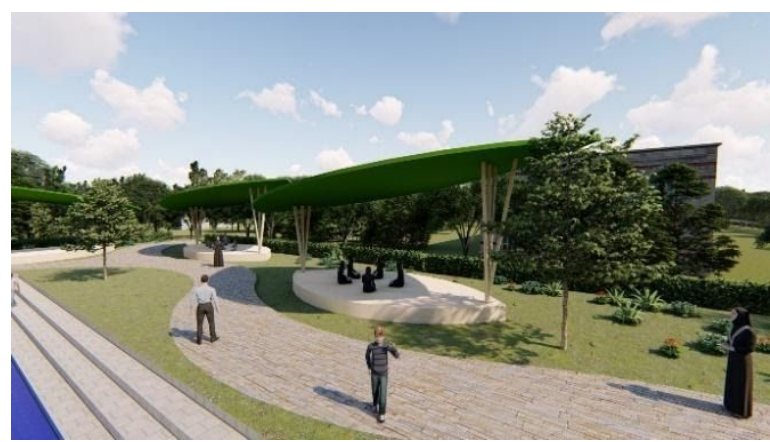

Gambar 14 Taman

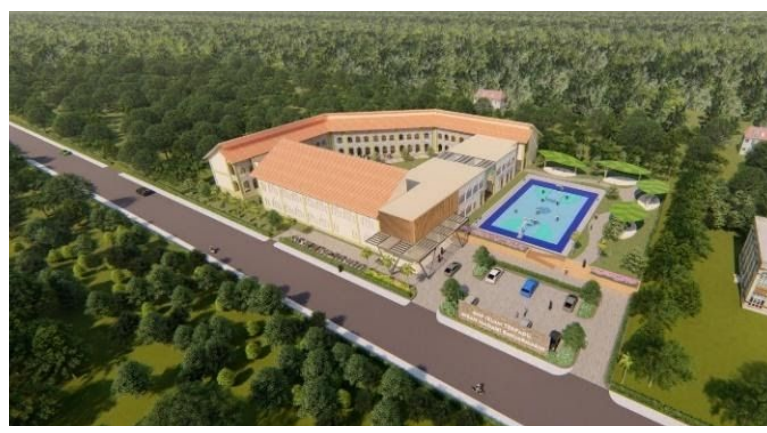

Gambar 15 Aerial View

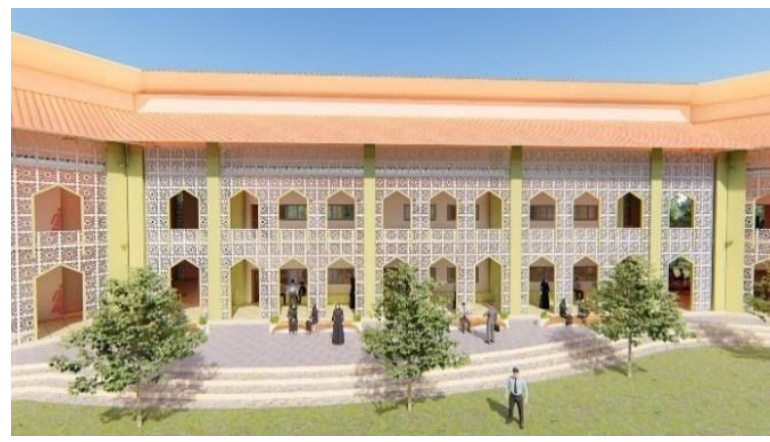

Gambar 16 Sun Shading

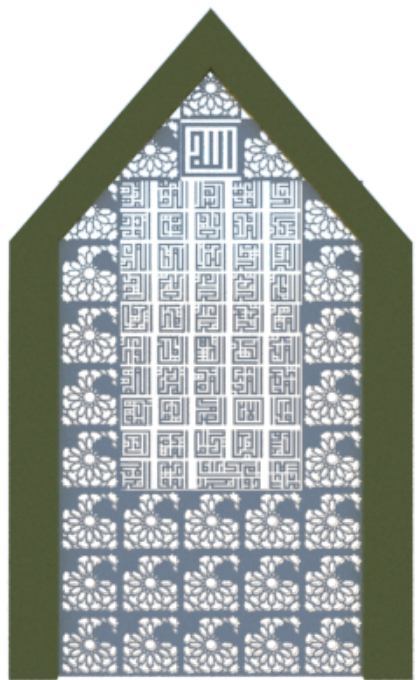

Gambar 17 Detail Sun Shading (GRC+Roaster)

\section{KESIMPULAN}

SMP Islam Terpadu Insan Madani Banjarmasin merupakan salah satu sekolah swasta islam di Banjarmasin. Sekolah ini didirikan oleh Yayasan Bina Insan Madani. Orangtua bukan hanya menginginkan pendidikan umum yang berkualitas untuk anak-anaknya, namun juga kebutuhan pendidikan agama.

Konsep Qur'an Educative Space merupakan konsep rancangan SMP Islam Terpadu Insan Madani Banjarmasin. Qur'an Educative Space dapat menciptakan semangat dan suasana edukatif yang membuat siswa kondusif dalam proses pembelajaran serta membantu siswa(i) dalam kemampuan tahfidz Al-Qur'an. Qur'an Educative Space dibagi atas 2 ruang, yaitu ruang luar dan ruang dalam. Ruang dalam adalah ruang-ruang untuk siswa belajar secara formal seperti ruang kelas, perpustakaan, dan laboratorium. Ruang luar merupakan ruang-ruang yang digunakan siswa untuk belajar secara informal seperti hafalan Al-Qur'an.

Ruang dalam diterapkan menggunakan dinding, plafon, lantai, dan tata letak perabot. Elemen-elemen tersebut diterapkan pada material, warna, tekstur, dan tata letak. Ruang luar merupakan penerapan pada elemen 
lansekap. Ruang luar diterapkan dalam penggunaan soft material, hard material, dan signage.

\section{DAFTAR PUSTAKA}

Jurnal Terapan Langkah-Langkah Pemrograman III. Universitas Gadjah Mada, Yogyakarta.

Muhaimin 2013. Rekonstruksi Pendidikan Islam; Dari Paradigma Pengembangan, Manajemen Kelembagaan, Kurikulum hingga Strategi Pembelajaran, Jakarta: Rajawali Pers.

Pena, William, et.al. 1998. Problem seeking, An Architectural Programming Primer, Boston Cahners Books International, Inc.

Peraturan Menteri Pendidikan Nasional Republik Indonesia No. 24 tahun 2007 tentang Standar Sarana dan Prasarana SD/MI, SMP/MTs, dan SMA/MA.

Peraturan Menteri Pendidikan dan Kebudayaan No. 68 tahun 2013 tentang Struktur Kurikulum SMP/MTs.

Wastuty, P. W., dkk. Ruang Sebagai Media Pembelajaran. Jurnal Teknika, Vol.2 No.2, April 2019.

White, Edward T, 1997, Introduction to Architectural Programming, University of Michigan, Architectural Media. 